\title{
HEAT EXCHANGER ANALYSIS FOR NONAZEOTROPIC REFRIGERANT MIXTURES
}

\author{
M. Y. Poz, Sc.D. \\ Vice President \\ Russian Association of Engineers for Heating, Ventilation, \\ Air Conditioning, Heat Supply and Building Thermal Physics (ABOK) \\ Moscow, Russia \\ J. C. Conklin, Ph.D., P.E. \\ Oak Ridge National Laboratory \\ Oak Ridge, Tennessee
}

\begin{abstract}
DISCLAIMER
This report was prepared as an account of work sponsored by an agency of the United States Government. Neither the United States Government nor any agency thereof, nor any of their employees, makes any warranty, express or implied, or assumes any legal liability or responsibility for the accuracy, completeness, or usefulness of any information, apparatus, product, or process disclosed, or represents that its use would not infringe privately owned rights. Reference herein to any specific commercial product, process, or service by trade name, trademark, manufacturer, or otherwise does not necessarily constitute or imply its endorsement, recommendation, or favoring by the United States Government or any agency thereof. The views and opinions of authors expressed herein do not necessarily state or reflect those of the United States Government or any agency thereof.
\end{abstract}

To be presented at the ASHRAE 1994 Annual Meeting

New Orleans, Louisiana January 23, 1994

Research sponsored by the Office of Building Technologies, U.S. Department of Energy under contract No. DE-AC05-84OR21400 with Martin Marietta Energy Systems, Inc. 


\begin{abstract}
A fundamental method for analyzing heat exchangers using pure refrigerants and nonazeotropic refrigerant mixtures is presented. The method allows for calculation of heat and mass transfer between moist air and nonazeotropic refrigerant mixtures and predicts local parameters of air and mixtures. Both single and two phase refrigerants can be analyzed with this method. Algorithms for the use of this model are presented. Data and calculated thermal performance for two conventional types of air-side geometries are also presented. The algorithms to calculate thermal performance of heat exchangers can be used for either conventional or enhanced geometries. A comparison of crossflow, cross-counterflow, and counterflow heat exchangers is given. The algorithms are sufficient for design and development of equipment using pure and mixed refrigerants.
\end{abstract}

\title{
FUNDAMENTALS
}

\section{Equations}

One characteristic of nonazeotropic refrigerant mixtures (NARMs) is a nonisothermal phase-change. Another characteristic is that at a given bulk composition, the compositions of the individual liquid and vapor phases vary during the phase-change process. For complete evaporation of a mixture of approximately $45 \%$ R-22 and $55 \%$ R-114 (by mass) as shown in Figure 1, the heat transfer process proceeds from the single-phase subcooled liquid (point A) to the single-phase superheated vapor (point B) through the two-phase vapor-liquid region (points C, D, and E). At each point in the two-phase region, the liquid and vapor components have different compositions, and hence have varying thermodynamic and transport properties during the phase-change process. For example, Figures 2, 3, and 4 show saturation enthalpies and pressures for various mixtures of R-22 and R-114. Figure 5 shows normalized enthalpy, defined as $\left(i-i_{b}\right) /\left(i_{d}-i_{b}\right)$, as a function of normalized temperature, defined as 
$\left(t-t_{b}\right) /\left(t_{d}-t_{b}\right)$ for the vapor and liquid phases of a $40 \%$ R-22/60\%R-114 (by mass) mixture. Thus, the two-phase region of a heat exchanger using NARMs requires careful analysis.

To analyze for NARM effects, a heat exchanger is first divided into three regions: single-phase liquid, two-phase vapor-liquid, and single-phase vapor. A one-dimensional model describing the process of heat and mass transfer between moist air and NARMs is given with the following system of differential equations.

$$
\begin{gathered}
\pm \frac{d t_{a}}{d \bar{x}}=\frac{\alpha_{l} A_{o u t}}{\left(m c_{p}\right)_{a}}\left(t_{a}-t_{w}\right) \\
\pm \frac{d i_{a}}{d \bar{x}}=\frac{\alpha_{l} A_{o u b}}{\dot{m}_{a}}\left[\left(t_{a}-t_{w}\right)+\frac{\alpha_{j}}{\alpha_{l}}\left(\omega_{b}-\omega_{b}\right)\right] \\
\pm \frac{d i_{m}}{d \bar{x}}=\frac{\left.\alpha_{m} A_{m} / t_{w}-t_{m}\right)}{\dot{m}_{m}} \\
\dot{m}_{m}=\dot{m}_{g}+\dot{m}_{l} \\
\dot{m}_{g 0} z_{g 0}+\dot{m}_{l 0} z_{l o}=\frac{\dot{i}_{g} \dot{m}_{g}+\dot{i}_{l} \dot{m}_{l}}{\dot{m}_{m}}
\end{gathered}
$$




$$
\begin{gathered}
i_{g}=f\left(p_{m}, t_{m}, z_{g}\right) ; i_{l}=f\left(p_{m}, t_{m}, z_{l}\right) \\
c_{g}=f\left(p_{m}, t_{m}, z_{g}\right) ; c_{l}=f\left(p_{m}, t_{m}, z_{l}\right) \\
z_{g}=f\left(p_{m}, t_{m}\right) ; z_{l}=f\left(p_{m}, t_{m}\right) \\
c_{p m}=\left(\frac{\partial i_{m}}{\partial t_{m}}\right)_{p}
\end{gathered}
$$

From equations (4) and (5), the mass flow rate of the vapor portion is given by

$$
\dot{m}_{g}=\frac{\dot{m}_{g 0}\left(z_{g 0}-z_{l 0}\right)+\dot{m}_{m}\left(z_{l 0}-z_{l}\right)}{z_{g}-z_{l}}
$$

At low mass diffusion rates, the Lewis analogy is valid (Domanski 1991; Poz and Bogoslovski 1984) and equation (2) can be transformed to

$$
\pm \frac{d i_{a}}{d \tilde{x}}=\frac{\alpha_{t} A_{\text {out }}}{\dot{m}_{a} c_{p a}}\left(i_{a}-i_{w}\right)
$$

Equations (1), (2), (3) and (12) for a linear model are transformed for latent heat transfer to

$$
\pm \frac{d i_{a}}{d \tilde{x}}=\frac{U_{i} A_{o u t}}{\dot{m}_{a} c_{p a}}\left(i_{a}-i_{m}\right)
$$

Equations (1), (2), (3) and (12) for a linear model are transformed for sensible heat transfer to 


$$
\pm \frac{d t_{a}}{d \bar{x}}=\frac{U_{b} A_{\text {out }}}{m_{a} c_{p a}}\left(t_{a}-t_{m}\right)
$$

The signs in Equations 1, 2, 3, 12, 13, and 14 are dependent on the heat exchanger arrangement (parallel flow, counterflow, or crossflow) and the heat transfer process (evaporation or condensation). This system of equations can be computation intensive: the thermophysical properties and heat transfer coefficients must be evaluated as the temperatures, pressures, and flow regimes vary during the phase-change process.

To simply the thermal performance calculation of heat exchangers with NARMs, the mixture refrigerant temperature is first nondimensionalized and then approximated with respect to a nondimensional heat transfer length $\bar{x}$, where $\bar{x}$ is the ratio of the local position from the refrigerant inlet to the total refrigerant flow length.

$$
\frac{t_{m}-t_{m 0}}{t_{l 0}-t_{g 0}}=a_{1} \bar{x}+a_{2} \bar{x}^{2}+\ldots+a_{n} \bar{x}^{n}
$$

Making a linear approximation, equation (15) can be simplified to

$$
\frac{t_{m}-t_{m 0}}{t_{l 0}-t_{g 0}}=a \bar{x}
$$

Using this linear approximation, equation (1) reduces for an evaporator to the following:

$$
-\frac{d t_{a}}{d \bar{x}}=\frac{\alpha_{t} A_{o u t}}{\left(\dot{m} c_{p}\right)_{a}}\left[\left(t_{a}-t_{m 0}\right)+\left(t_{l 0}-t_{m 0}\right) a \bar{x}\right]
$$


Equation (17) can be nondimensionalized, where the grouping in front of the squarebracketed term on the right-hand-side is recognized as the "number of transfer units" $(N)$ on the air side (Kays and London 1984). Thus,

$$
-\frac{d \theta_{a}}{d \bar{x}}=N_{a}\left(\theta_{a}+\theta_{m 0}+a \bar{x}\right)
$$

where

$$
\theta_{a}=\frac{t_{a}-t_{l 0}}{t_{a 0}-t_{l 0}} \text { and } \theta_{m 0}=\frac{t_{g 0}-t_{L 0}}{t_{a 0}-t_{l 0}}
$$

The solution of equation (18) is

$$
\theta_{a}=e^{-N_{\alpha}}\left(-\int N_{a} \theta_{m 0} a x e^{N_{\dot{\alpha}}} d x+A^{\prime}\right)
$$

or

$$
\theta_{a}=e^{-N_{x}}\left[N_{a} \theta_{m 0} a\left(1+N_{a} \bar{x}\right) \frac{e^{N_{\sigma_{j}}}}{N_{a}^{2}}+A^{\prime}\right]
$$

The constant of integration $A^{\prime}$ can be found using the boundary condition $\theta_{a}=1$ at $x=0$.

$$
A^{\prime}=1-\frac{\theta_{m 0} a}{N_{a}}
$$

Thus, the air temperature from equation (21) for a linear refrigerant temperature is

$$
\theta_{a}=\left(1-\frac{\theta_{m 0} a}{N_{a}}\right) e^{-N_{j} \bar{x}}+\theta_{m 0} a\left(\bar{x}+\frac{1}{N_{a}}\right)
$$

When the relative refrigerant temperature is zero, $\theta_{\mathrm{m} 0}=0$, equation (23) reduces to 


$$
\theta_{a}=e^{-N_{0} z}
$$

Equation (24) is appropriate for heat exchangers with isothermal fluids, such as pure refrigerants undergoing a change in phase.

Proceeding in the same fashion by approximating the dimensionless temperature profile with a quadratic polynomial, the solution of equation (18) is then

$$
\theta_{a}=\left[1-\theta_{m 0}\left(\frac{a_{1}}{N_{a}}+\frac{a_{2}}{N_{a}^{2}}\right)\right] e^{-N_{s}+}+\theta_{m 0}\left[a_{1}\left(\frac{1}{N_{a}}+\bar{x}\right)+a_{2}\left(\bar{x}^{2}-2 \frac{\bar{x}}{N_{a}}+\frac{2}{N_{a}^{2}}\right)\right]
$$

Equations (23) and (25) give the temperature distribution along the heat exchanger. The choice of linear or quadratic refrigerant approximate temperature profile is a decision for the user. The linear approximation has an advantage of speed while the quadratic approximation has higher accuracy. The quadratic approximation for the refrigerant temperature profile was used for the results presented here. The coefficients $a$, or $a_{1}$ and $a_{2}$, are determined from an accurate, and perhaps more involved, property calculation for each tube row of the heat exchanger. Thus, equations (23) and (25) give the air temperature distribution for each refrigerant tube row or segment when a "step by step" method is used.

\section{Outside and inside heat transfer coefficients}

To use the algorithms presented in the: preceding section, the outside and inside heat transfer coefficients must be known. Two general types of conventional outside heat transfer surfaces were examined here: plain fins on round tubes (Briggs and Young 1962, Nir 1991, Gray and Webb 1986, Poz and Bogoslovsky 1984), and offset-strip-fins (OSF) on oval tubes (Manglik and Bergles 1990). 
Several heat transfer coefficient correlations from the literature for the inside of tubes are available. The results presented here were obtained with the Petukhov-Popov (1970) correlation for the single-phase refrigerants and with the Kandlikar $(1990,1991)$ correlations for two-phase fluids. The heat transfer coefficients for the nonazeotropic refrigerant mixtures in smooth tubes are generally lower than those for the pure refrigerants for both evaporation and condensation. A simple approach (Granryd 1991) is used here to account for this degradation in heat transfer coefficient.

Changes in pressure due to friction, acceleration, and gravity effects are calculated. The Lockhart and Martinelli (1949) method is used to calculate the total pressure drop for refrigerant side.

\section{Thermodynamic and transport properties of pure and mixed refrigerants}

Three methods may be used to compute the thermodynamic properties of pure and mixed refrigerants. The first uses a general equation of state for liquid and vapor regions. The algorithms of Morrison and McLinden (1986) that implement the Carnahan-StarlingDesantis (CSD) equation of state to compute the thermodynamic properties are representative of this first method. The second method is described by Perelshtein (1984) or Nir (1990). This method uses different equations for the liquid and vapor regions. The third method is a polynomial fit to published data.

The transport properties can be computed in the same three characteristic manners. For the first method, some of the algorithms given by Jung and Radermacher (1991) use an equation of state, or thermodynamic values computed with an equation of state. The second method uses equations described by Perelshtein and Parushin (1984) and Nir (1990). The third method, as before, is a polynomial fit to measured or published data. 
For heat exchangers using nonazeotropic refrigerant mixtures, an iterative method is used to calculate the pressure at each segment of the heat exchanger. As a result, the thermodynamic properties must be calculated at each intermediate point in the heat exchanger. In many applications, the temperature variation is small over the incremental, intermediate points in the heat exchanger. In this case, polynomial approximations of the thermodynamic and transport properties can be employed to reduce the calculation time. A simple, often applied approximation is an ideal mixture average of the pure component values, weighted by the mass or mole fraction:

$$
\Phi_{m b}=z \Phi_{r 1}+(1-z) \Phi_{r 2}
$$

where the subscript $l$ denotes linear.

Such mixing rules can work well if there are no strong intermolecular interactions. Figures 6 and 7 show the difference $(\Delta \Phi)$ between the calculated mixture property $\left(\Phi_{m}\right)$ and the property given by linear combination $\left(\Phi_{m b}\right)$ of a mixture of R-22 and R-114 in the temperature range of $-40^{\circ} \mathrm{C}$ to $80^{\circ} \mathrm{C} . \Delta \Phi$ is defined as follows:

$$
\Delta \Phi=\frac{\Phi_{m}-\Phi_{m l}}{\Delta \Phi_{\max }}
$$

The composition at maximum error varies from $20 \%$ to $70 \% \mathrm{R}-114$, depending on the property. Polynomial approximations-sixth order in this case-were developed to calculate the mixture property difference $\Delta \Phi$ in the temperature range of $-40^{\circ} \mathrm{C}$ to $80^{\circ} \mathrm{C}$ for the liquid and vapor. Thus, the linear approximation between the pure component values for this mixture of R-22 and R-114 yields agreement to within $1 \%$ for these properties. 


\section{SOLUTION METHODOLOGY}

The equations presented in the preceding section along with analogous equations for crossflow have been implemented in a set of computer algorithms. The simulation is based on an iterative, or step-by-step approach. Performance of each tube row or segment is analyzed independently. The method starts with the known refrigerant and air inlet parameters for the first tube row or segment of the heat exchanger. The exit conditions of the previous tube row or segment are the inlet conditions for the next tube row or segment. For counterflow or cross-counterflow heat exchangers, iterations are necessary, since the air inlet is at the refrigerant outlet. The computer subroutines fall into four general categories:

- to determine air-side heat and mass transfer coefficients and pressure drop;

- to determine thermodynamic and transport properties of pure and mixed refrigerants;

- to determine tube-side heat and mass transfer coefficients and pressure drop;

- to determine local parameters of air and refrigerant.

The thermodynamic and transport properties are determined with three described methods. For the results presented here, sixth order polynomial approximations were used, in general. The coefficients of the polynomial fits were determined using published data (ASHRAE 1989; Jung and Radermacher 1991) and computed results from the CSD equation of state (Morrison and McLinden 1986). The inside heat transfer coefficients and pressure drops are calculated locally for heat exchangers using water, coolants (brines), and pure and mixed refrigerants (single-phase and two-phase). Changes in pressure due to friction, acceleration, and gravity effects are calculated. The local heat transfer coefficient and pressure drop correlations for smooth tubes described earlier are used as appropriate for the local conditions in the heat exchanger. Improved correlations, including enhanced surfaces, can be implemented in the subroutines when available. Parameters for the refrigerant and the air are calculated using the linear model. 
In this manner, the local temperatures of interest can be calculated for the refrigerant in each segment of heat exchangers for dry and wet air. For the following results, only dry air was used.

\section{RESULTS}

The computer subroutines have been used to calculate the thermal performance of two evaporators based on conventional plain fins and enhanced offset-strip fin (OSF) air-side geometries. The air flows in a crossflow direction with the refrigerant flowing in parallel tubes. The air, outside heat transfer surface has a fin thickness of $0.1 \mathrm{~mm}$ and a fin pitch of $500 \mathrm{~m}^{-1}$. The inside diameter of the round tubes in the plain fin heat exchanger is $8 \mathrm{~mm}$. The oval tubes have the same cross-section inside flow area as that of the round tubes. The tubes are arranged in a rectangular pitch with a transverse tube spacing of $30 \mathrm{~mm}$ and a longitudinal tube pitch of $15 \mathrm{~mm}$. Both the fins and tubes are aluminum. The air-which is dry-has a velocity of $5 \mathrm{~m} / \mathrm{s}$ in a free-flow section for both the round tubes and the oval tubes. The refrigerant is a nonazeotropic refrigerant mixture of R-22 and R-114, with a bulk composition of $50 \%$ by mass. The refrigerant was evaporated from a saturated liquid to a saturated vapor.

Figures 8 and 9 show the temperatures of the dry air and the refrigerant as a function of dimensionless length of the crossflow evaporators for 1 to 5 parallel rows of tubes. The refrigerant mass flow rate was varied to meet the heat load resulting from specifying the constant air velocity in a free-flow section. From comparison of Figures 8 and 9, the refrigerant temperature profile is affected by the air-side enhancement and the number of parallel-flow tube rows. The refrigerant temperature is nonlinear with respect to the flow length, and is increasingly nonlinear as the number of tube rows increases. 
Figures 10 and 11 show the varying composition of mixture as a function of dimensionless length of evaporator. Interestingly, the curvature of the enhanced offset-stripfin evaporator composition is predominately concave, while the curvature of the plain-fin evaporator is concave for the one-row case and convex for the five row case. This indicates different rates of heat exchange in the two different evaporators, which is not unexpected. Thus, analysis of the phase-change process of NARMs in heat exchangers is more involved than for pure refrigerants.

Table 1 and Figure 12 summarize the thermal performance of these two evaporators.

Table 1. Thermal performance of two evaporators

\begin{tabular}{||l|c|c|c|c|c|c||}
\hline number of tube rows & \multicolumn{2}{|c|}{1} & \multicolumn{2}{c|}{3} & \multicolumn{2}{c||}{5} \\
\hline air-side geometry & plain & OSF & plain & OSF & plain & OSF \\
\hline $\begin{array}{l}\text { outside heat transfer } \\
\text { surface area per unit } \\
\text { face area, } \mathrm{m}^{2} / \mathrm{m}^{2}\end{array}$ & 32.18 & 23.56 & 96.56 & 70.7 & 160.9 & 117.8 \\
\hline $\begin{array}{l}\text { air flow rate per unit } \\
\text { face area, } \mathrm{kg} /\left(\mathrm{m}^{2} \cdot \mathrm{s}\right)\end{array}$ & 1.93 & 4.17 & 1.93 & 4.17 & 1.93 & 4.17 \\
\hline $\begin{array}{l}\text { mixture flow rate per } \\
\text { unit face area, } \mathrm{kg} /\left(\mathrm{m}^{2} \cdot \mathrm{s}\right)\end{array}$ & 0.09303 & 0.1114 & 0.1861 & 0.1502 & 0.2234 & 0.3647 \\
\hline $\begin{array}{l}\text { heat transfer per unit } \\
\text { face area, } \mathrm{kW} / \mathrm{m}^{2}\end{array}$ & 18.66 & 26.19 & 40.85 & 59.8 & 49.8 & 83.51 \\
\hline
\end{tabular}

Thus, an offset-strip-fin air-side evaporator can increase the heat transfer compared with a plain-fin evaporator by a factor of 1.67 for five tube rows with a given face area at an air velocity of $5 \mathrm{~m} / \mathrm{s}$ in the free-flow cross-section.

The computer subroutines have been used to compare the temperature effectiveness of different heat exchanger arrangements for the specific geometry, refrigerant mixture, and operating conditions described previously. These results include the nonlinear thermophysical property effects of this particular nonazeotropic refrigerant mixture. Figures 13 and 14 show 
the ratio of $\theta_{\mathrm{a}}$ at the heat exchanger outlet for cross-counterflow and crossflow (air unmixed between passes) heat exchanger arrangements to $\theta_{a}$ for counterflow plotted against the ratio of heat capacities. The heat capacity ratio is defined as the following:

$$
W=\frac{\left(\dot{m} c_{p}\right)_{a}}{\left(m c_{p}\right)_{m}}
$$

The difference between counterflow and both crossflow and cross-counterflow heat exchangers incrnases when the value of $N$ increases and decreases as the number of tube rows increases. For cross-counterflow heat exchangers, the maximum difference is only $6 \%$ when there are two tube rows and $N$ is four and decreases to $2 \%$ when $N$ is one.

For crossflow, as shown in Figure 13, the maximum difference takes place when the value of $W$ is approximately one. Because of the nonisothermal phase-change of NARMs, a non-zero value of the heat capacity ratio can exist for evaporators or condensers (Granryd and Conklin 1990). When $W$ is equal to one, this is known as a "balanced" heat exchanger. The difference between counterflow and crossflow for a balanced heat exchanger is shown in Figure 14. When $N$ is four with one tube pass, the ratio of temperature effectiveness is $78 \%$, and increases to $93 \%$ for five tube passes.

The relative values of effectiveness shown in Figures 13 and 14 are specific to the particular refrigerant mixture, in this case R-22 and R-114, $50 \%$ by mass. Different mixtures with different temperature-enthalpy relationships will show different values of relative effectiveness. Also, all heat transfer enhancement effects are included.

Thus, the relative effectiveness of any particular heat exchanger arrangement can be determined with respect to counterflow using any particular refrigerant mixture. Whether or not the relative effectiveness can be considered as a sufficiently close approximation to counterflow should be determined with an overall refrigeration cycle analysis, because the 
Coefficient of Performance (COP) of a cycle using mixtures can be very sensitive to the heat exchanger arrangement and size (Rice 1993).

\section{CONCLUSIONS}

A reasonable level of accuracy is obtained with the subject fundamental principles model of air-refrigerant heat exchangers. Algorithms and computer subroutines allow calculation of the local parameters of refrigerants and air for well-known air-side geometries and different types of coolants (water, brines, refrigerant, refrigerant mixtures). Crossflow, counterflow, and parallel flow arrangements with mixed and pure refrigerants may be analyzed.

A sample enhanced air-side surface was shown to allow an increase in heat capacity or a decrease in the number of tube rows in evaporators by a factor of 1.7 for a given frontal area as compared to plain-fins. Different types of air-side geometries are presently being investigated.

The effect of the temperature profile of any particular refrigerant mixture can be substantial on the relative effectiveness of a particular flow arrangement compared to counterflow. All specific operating parameters must be investigated before a determination of $\mathrm{COP}$ can be made for the refrigeration cycle.

\section{ACKNOWLEDGMENT}

This work was sponsored by the Office of Building Technologies, U. S. Department of Energy under contract No. DE-AC05-84OR21400 with Martin Marietta Energy Systems, Inc. 


\section{NOMENCLATURE}

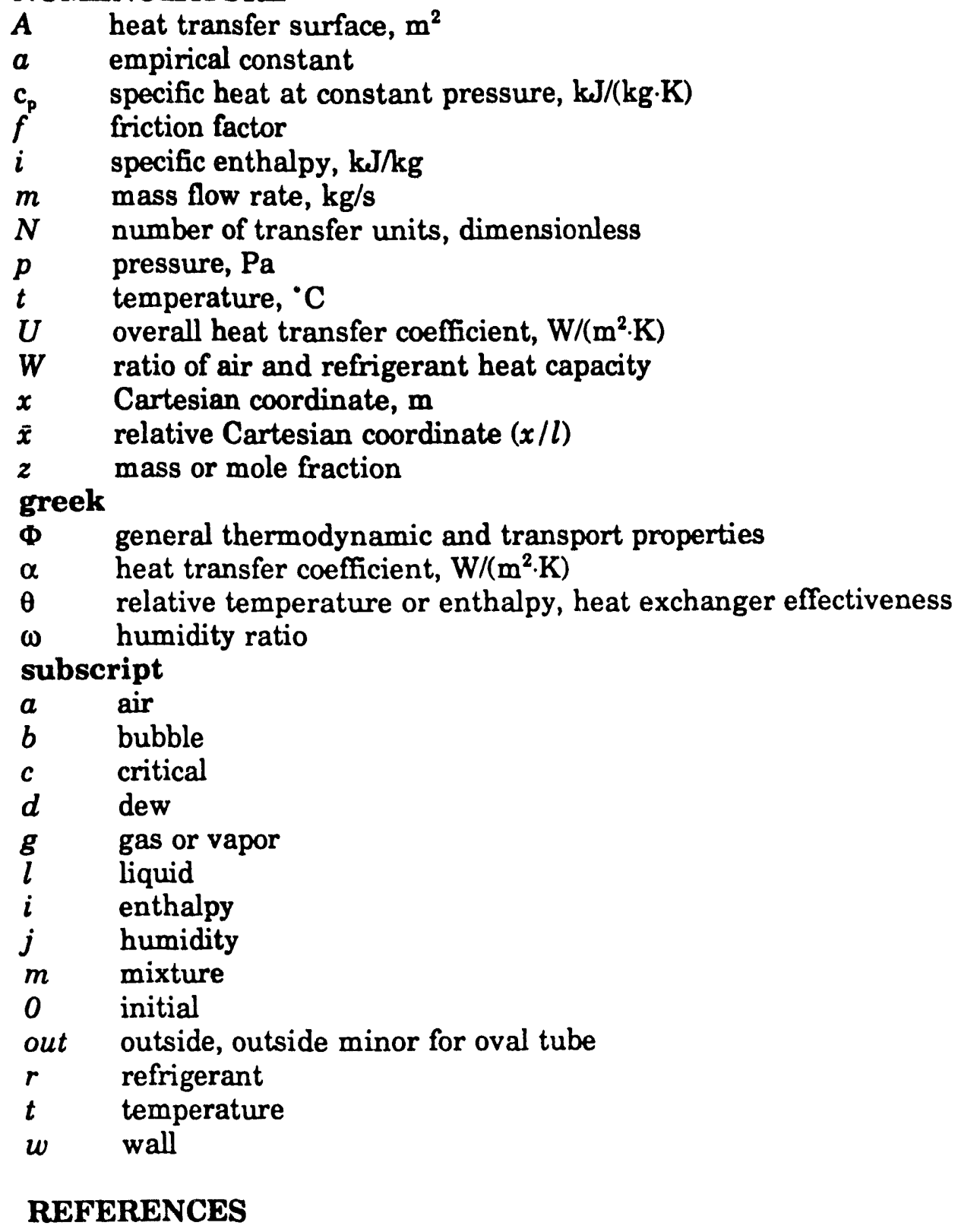

ASHRAE. 1989 . Handbook of fundamentals, chapter 16.

Briggs, D. E. and E. H. Young. 1962. Convectional heat transfer and pressure drop of air flowing across triangular pitch banks of finned tubes. 5th AICHE/ASME national heat transfer conference. Houston, Texas.

Domanski, P. A. 1991. Simulation of an evaporator with nonuniform one dimensional air distribution. ASHRAE Transactions 97(1).

Gray, D. L. And R. L. Webb. 1986. Heat transfer and friction correlation for plate fin-andtube heat exchangers having plain fins. Heat Transfer Proceedings 8th International Heat Transfer Conference, 2745-2750. 
Granryd, E. and J. C. Conklin. 1990. Thermal performance analysis for heat exchangers using nonazeotcopic refrigerant mixtures, Heat Transfer in Advanced Energy Systems, HTDVol. 151, AES-Vol. 18 R. F. Boehm and G. Vliet, eds., The American Society of Mechanical Engineers, New York, pp. 25-32.

Granryd, E. 1991. Heat transfer in flow evaporation of non azeotropic refrigerant mixtures-a theoretical approach. Proceedings of the XVIII International Congress of Refrigeration, August 10-17, Montreal, Quebec, Vol. III, pp. 1330-1334..

Jung, D. S. and R. Radermacher. 1991. Transport properties and surface tension of pure and mixed refrigerants. ASHRAE Transactions 97(1):90-99.

Kays, W. M. and A. L. London. 1984. Compact Heat Exchangers, 3rd ed. McGraw-Hill, New York.

Kandlikar, S. G. 1991. A model for correlating flow boiling heat transfer in augmented tubes and compact evaporators. J. Heat Trans., Vol 113:966-972.

Kandlikar, S. G. 1990. A general correlation for saturated two-phase flow boiling inside horizontal and vertical tubes. J. Heat Trans, Vol 112:219-228.

Lockhart, R. W. and R. C. Martinelli. 1949.Proposed correlation of data for isothermal twophase, two-component flow in a pipe, Chem. Eng. Progr., Vol. 45, p. 39.

Manglik, R. M. and A. E. Bergles. 1990. The thermal-hydraulic design of the rectangular offset-strip-fin compact heat exchangers. Compact Heat Exchangers, R. K. Shah, A. D. Kraus, and D. Metzger, eds., Hemisphere Publishing Corporation, New York, pp. 123-150.

Mclinden, M., J. Gallagher, and G. Morrison. 1989. NIST Thermodynamic Properties of refrigerants and refrigerant mixtures. National Institute of Standards and Technology. U.S. Department of Commerce.

Nir, A. 1991. Heat transfer and friction factor correlation for crossflow over staggered finned tube banks. Heat Transfer Engineering, 12(1):43-58.

Nir, A. 1990.Computer program "ESTER"

Perelshtein, I. I., and E. B. Parushin. 1984. Thermodynamic and thermophysical properties of refrigerants for refrigerators and heat pumps,, Legkay and Pishevay promishlenost, Moscow.

Petukov, B. S. 1970. Heat transfer and friction in turbulent pipe flow with variable physical properties. Advances in Heat Transfer, Academic Press, New York, 6:503-664.

Poz, M. Y. and V. N. Bogoslovsky. 1984. Thermal physics of heat exchangers for HVAC systems. Stroyisdat, Moscow.

Rice, C. K. 1993. Influence of $\mathrm{HX}$ size and augmentation on performance potential of mixtures in air-to-air heat pumps. ASHRAE Transactions 99(2) 


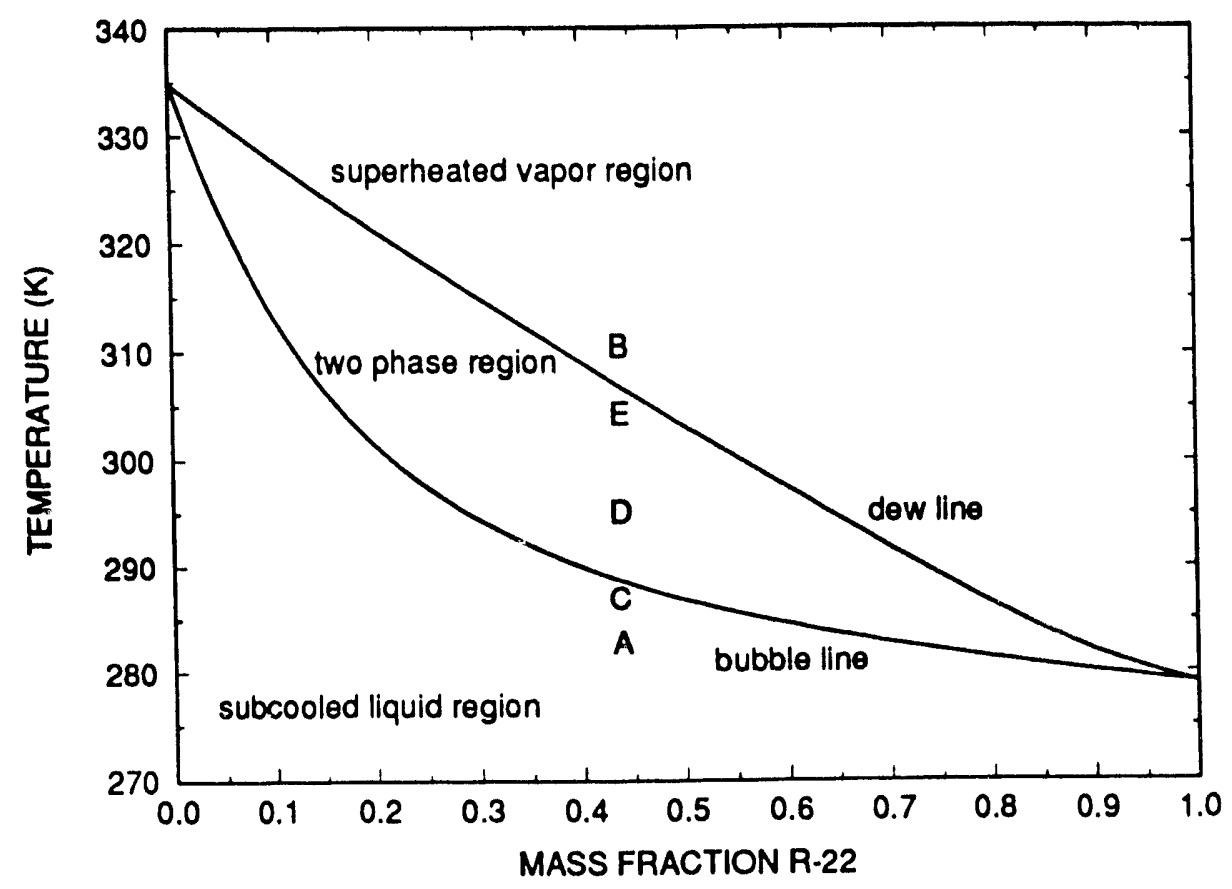

Figure 1 R-22/R-114 saturation lines at $600 \mathrm{kPa}$.

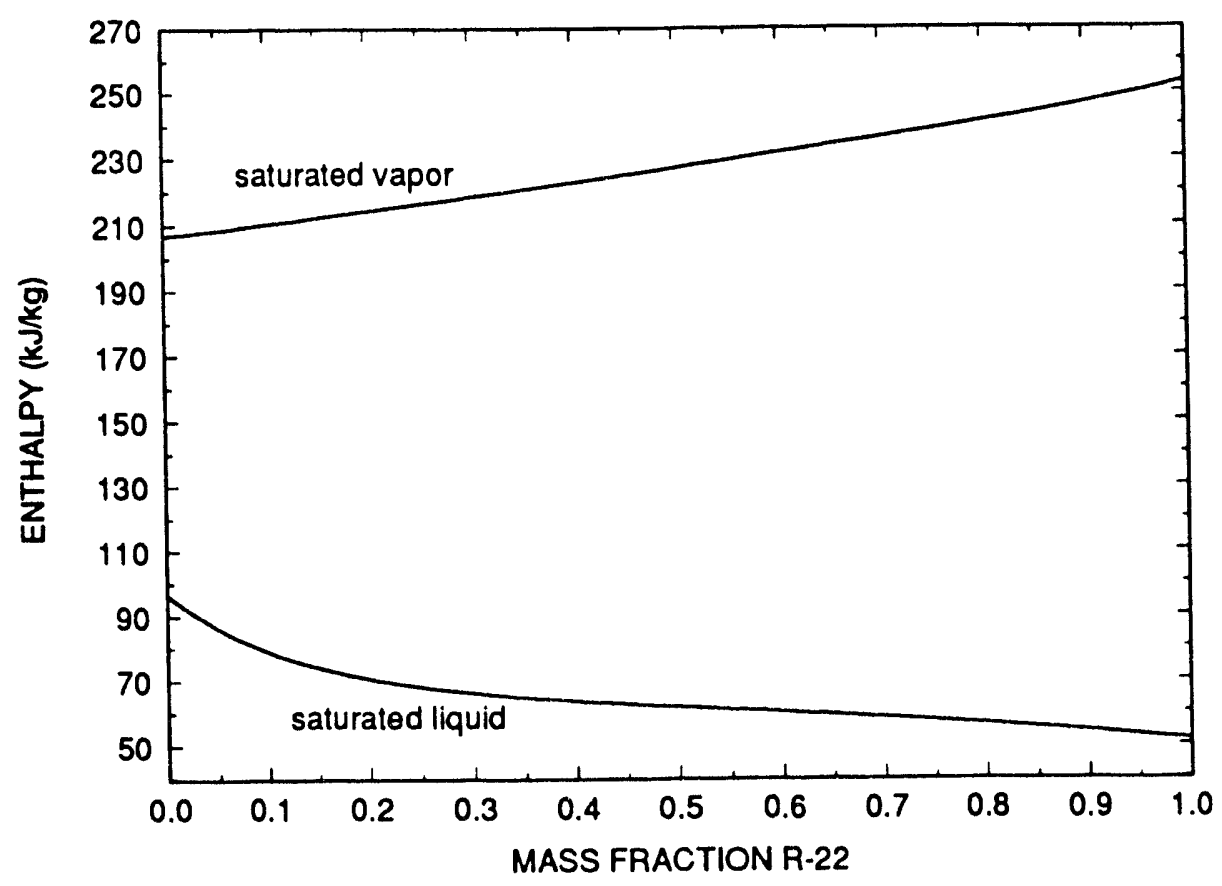

Figure 2 Saturation enthalpy of R-22/R-114 at $600 \mathrm{kPa}$. 

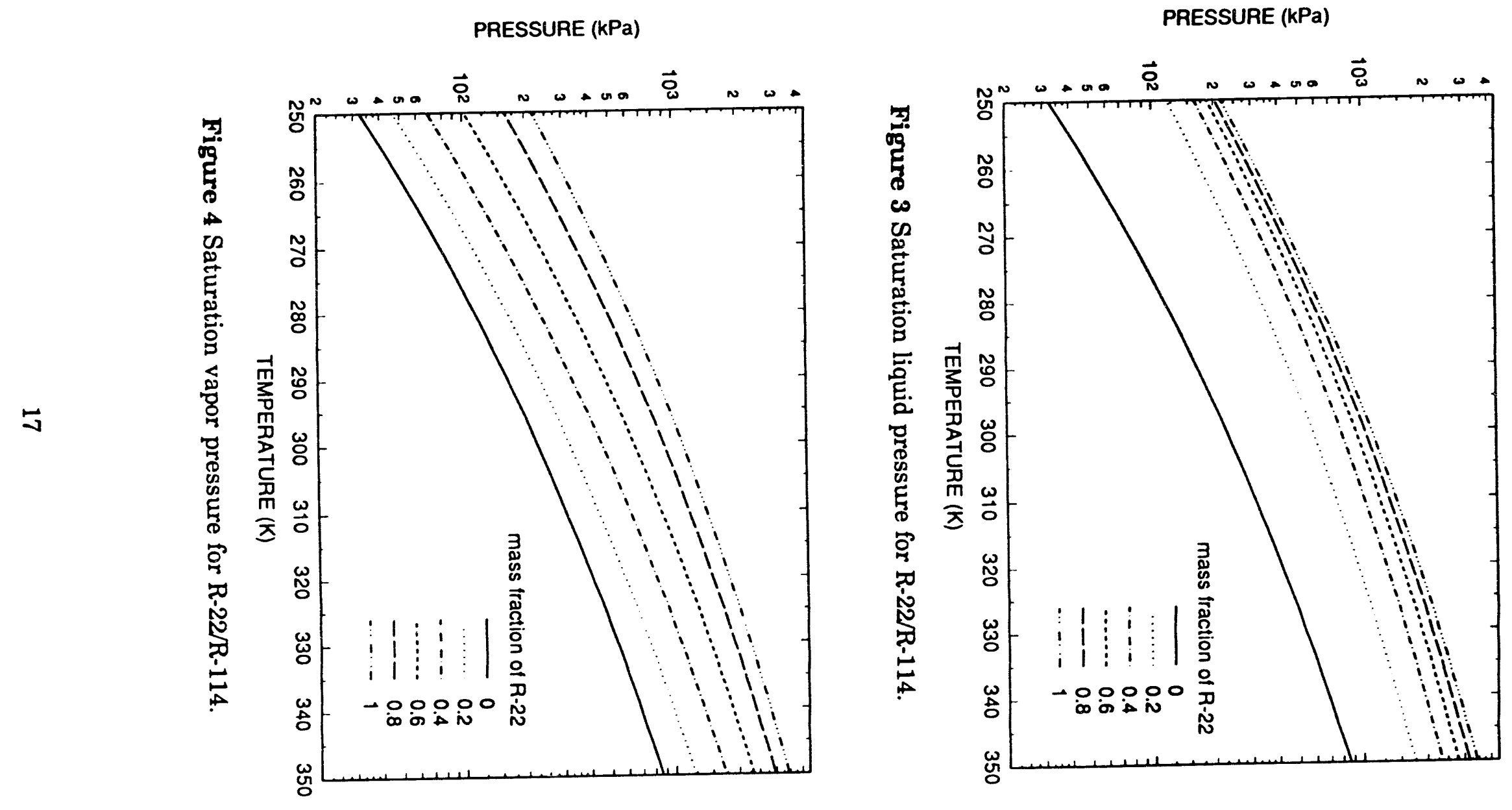


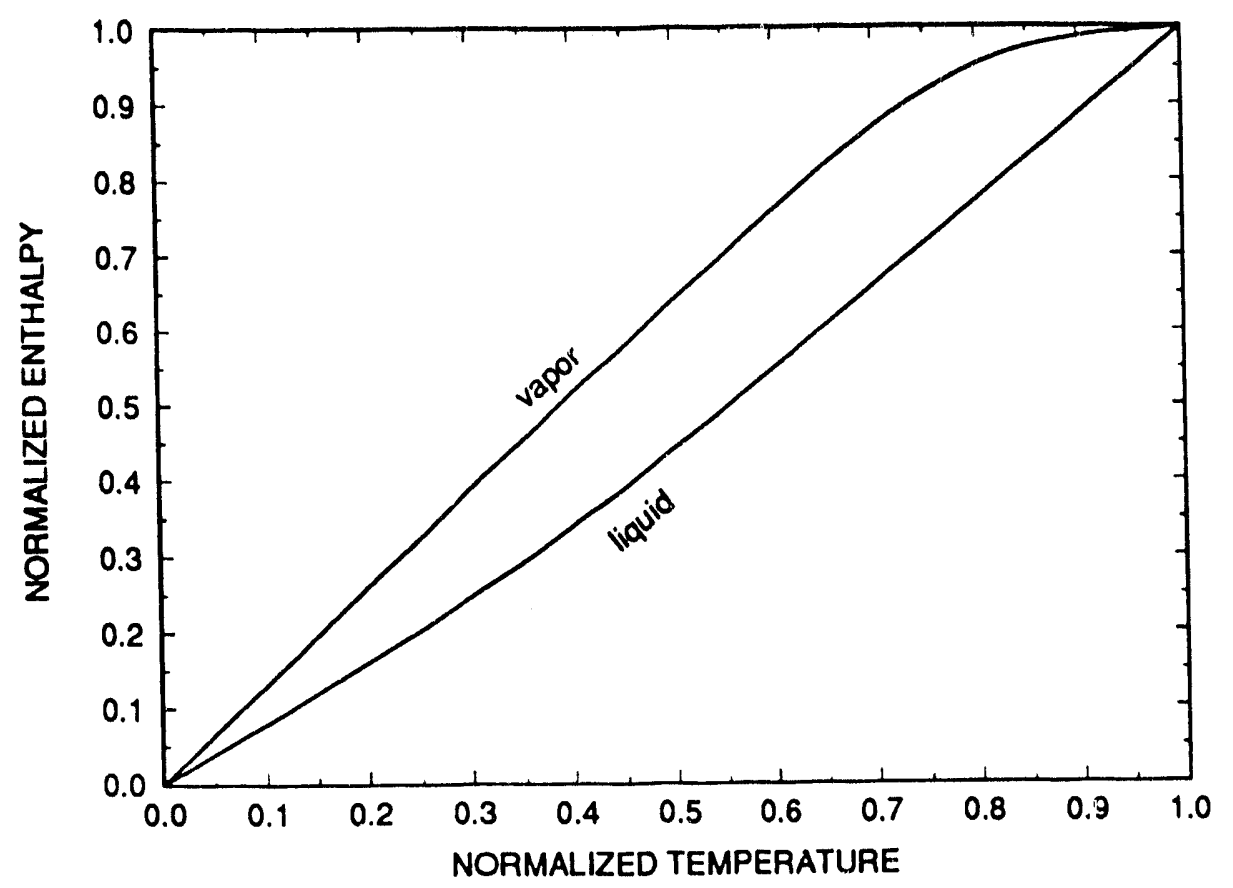

Figure 5 Enthalpy of R-22/R-114 (40\%/60\% mass) at $600 \mathrm{kPa}$.

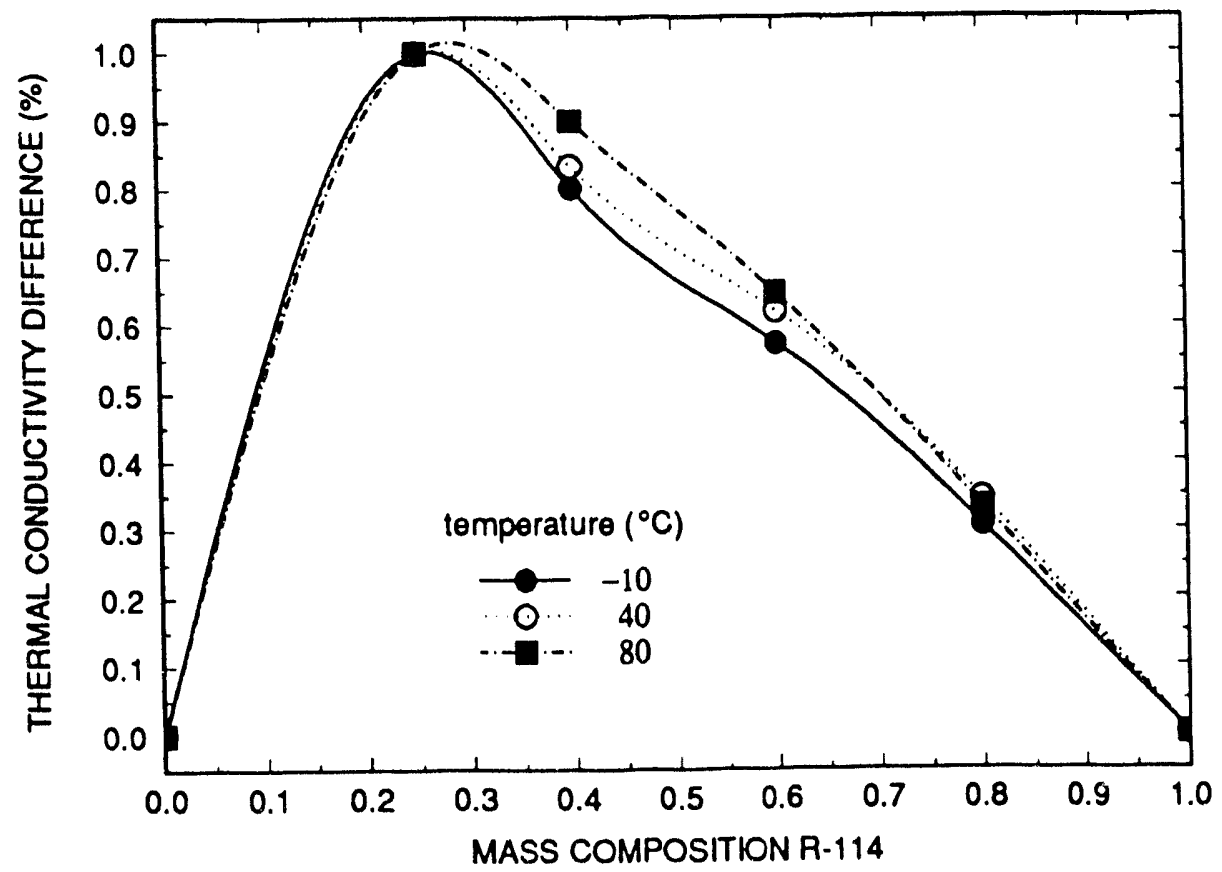

Figure 6 Linear and nonlinear thermal conductivity difference. 


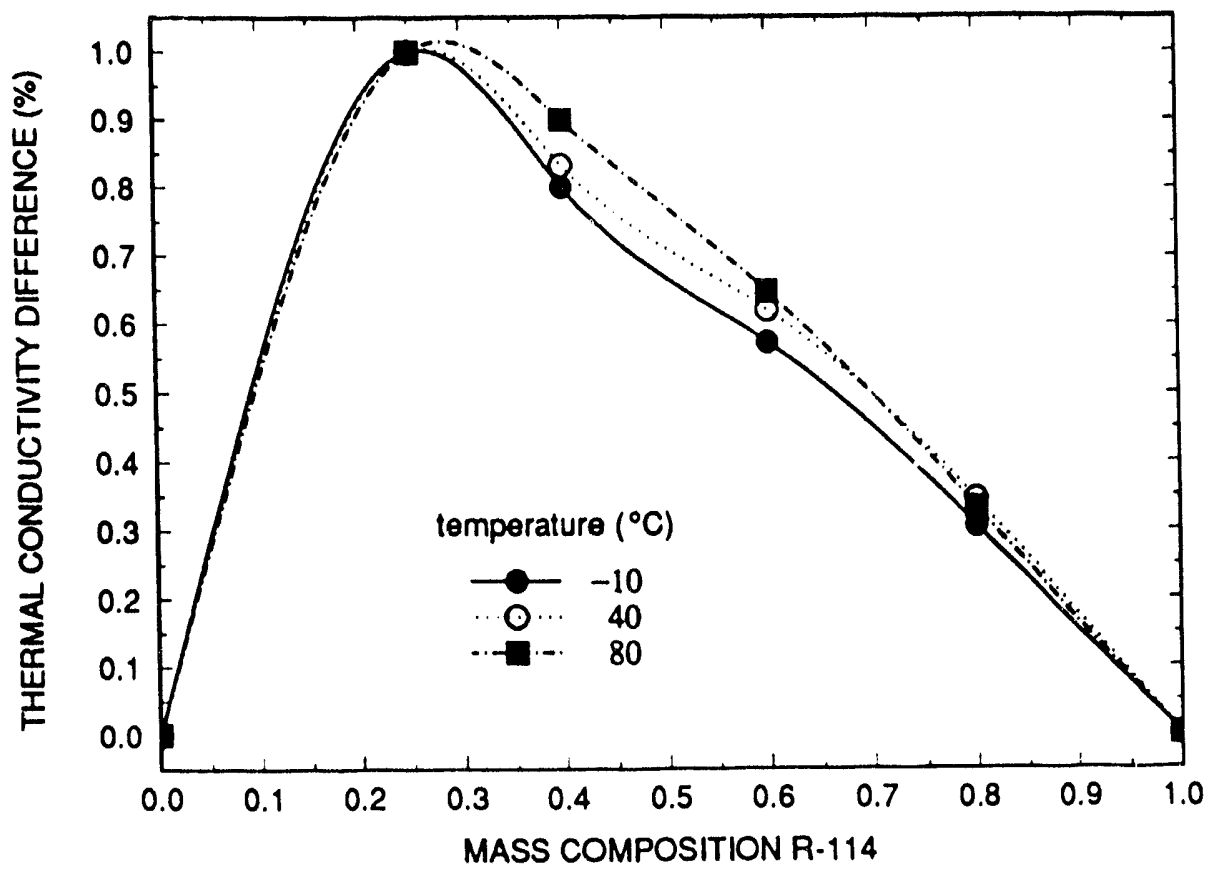

Figure 7 Linear and nonlinear saturation vapor pressure difference.

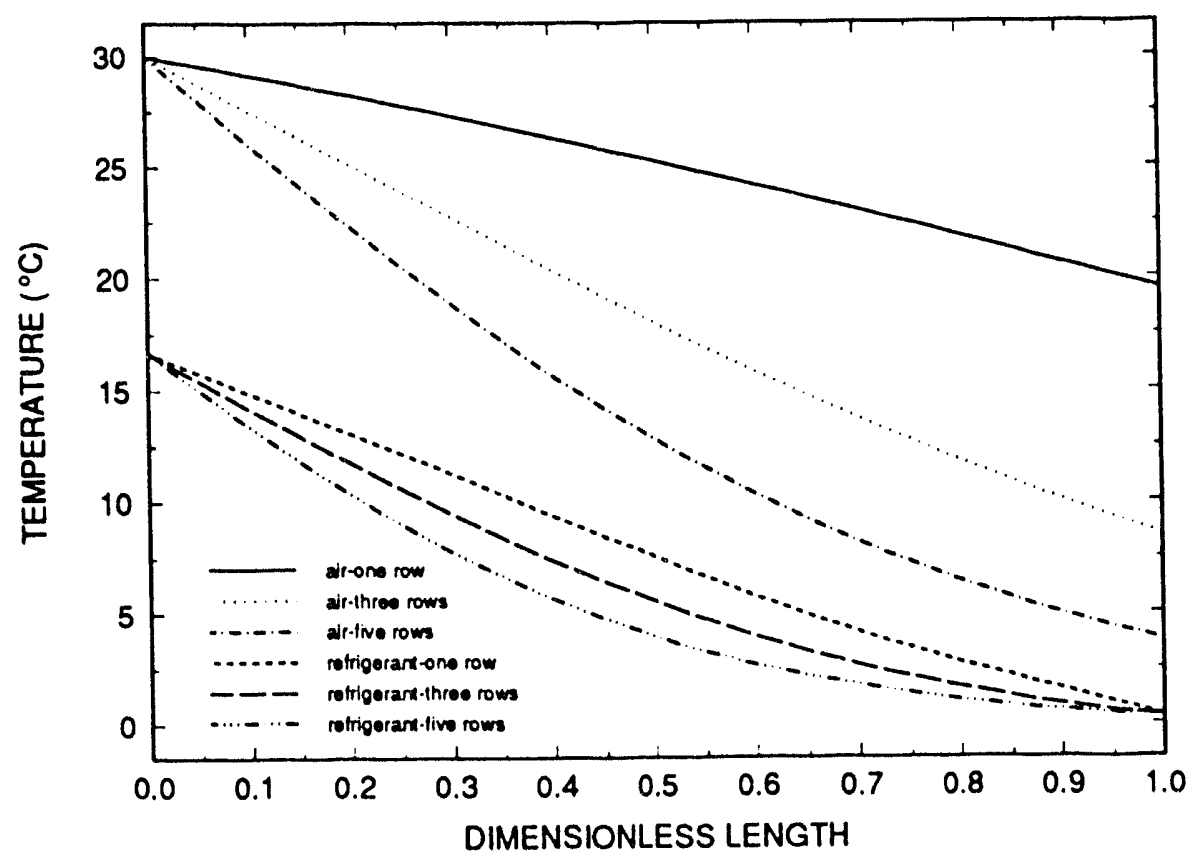

Figure 8 Temperature profiles for offset-strip-fin evaporator. 


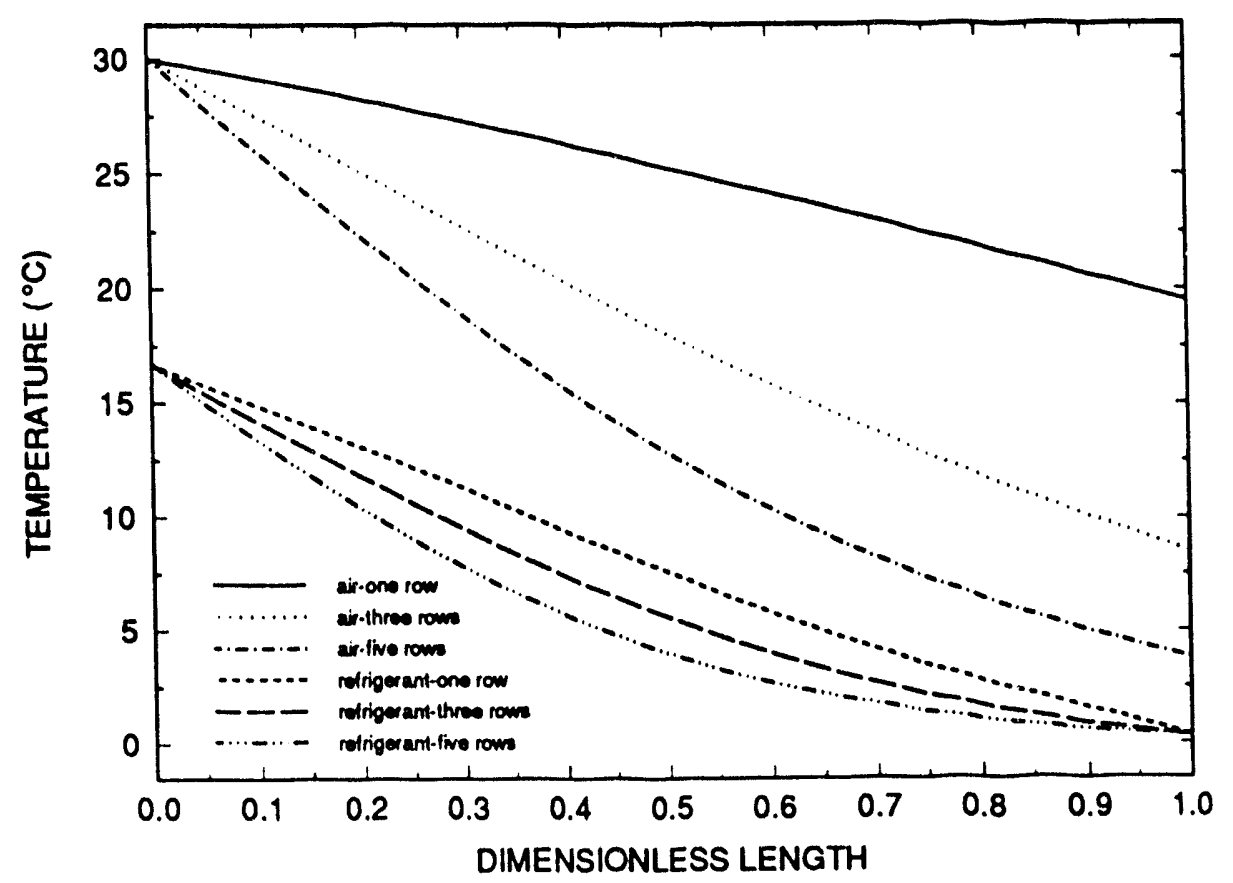

Figure 9 Temperature profiles for plain-fin evaporator.

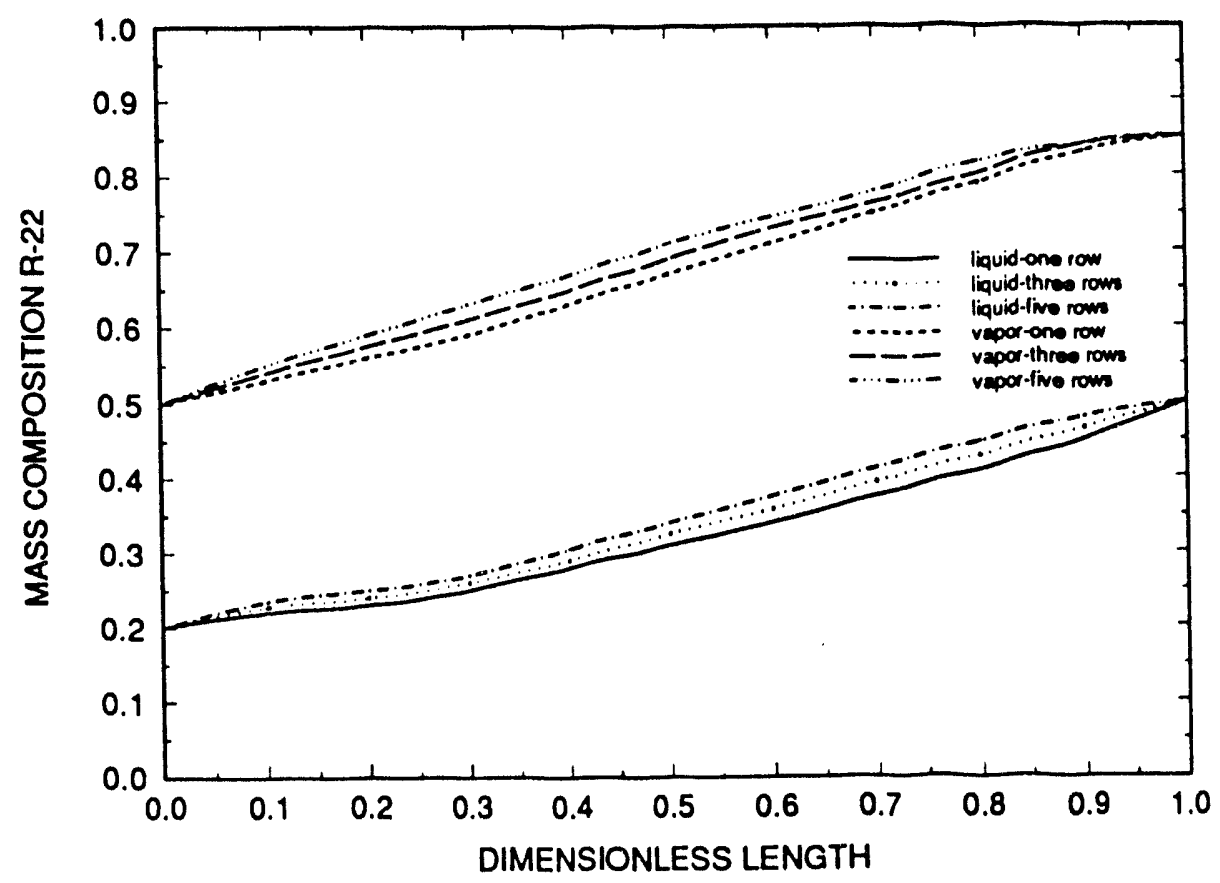

Figure 10 Refrigerant composition for offset-strip-fin evaporator. 


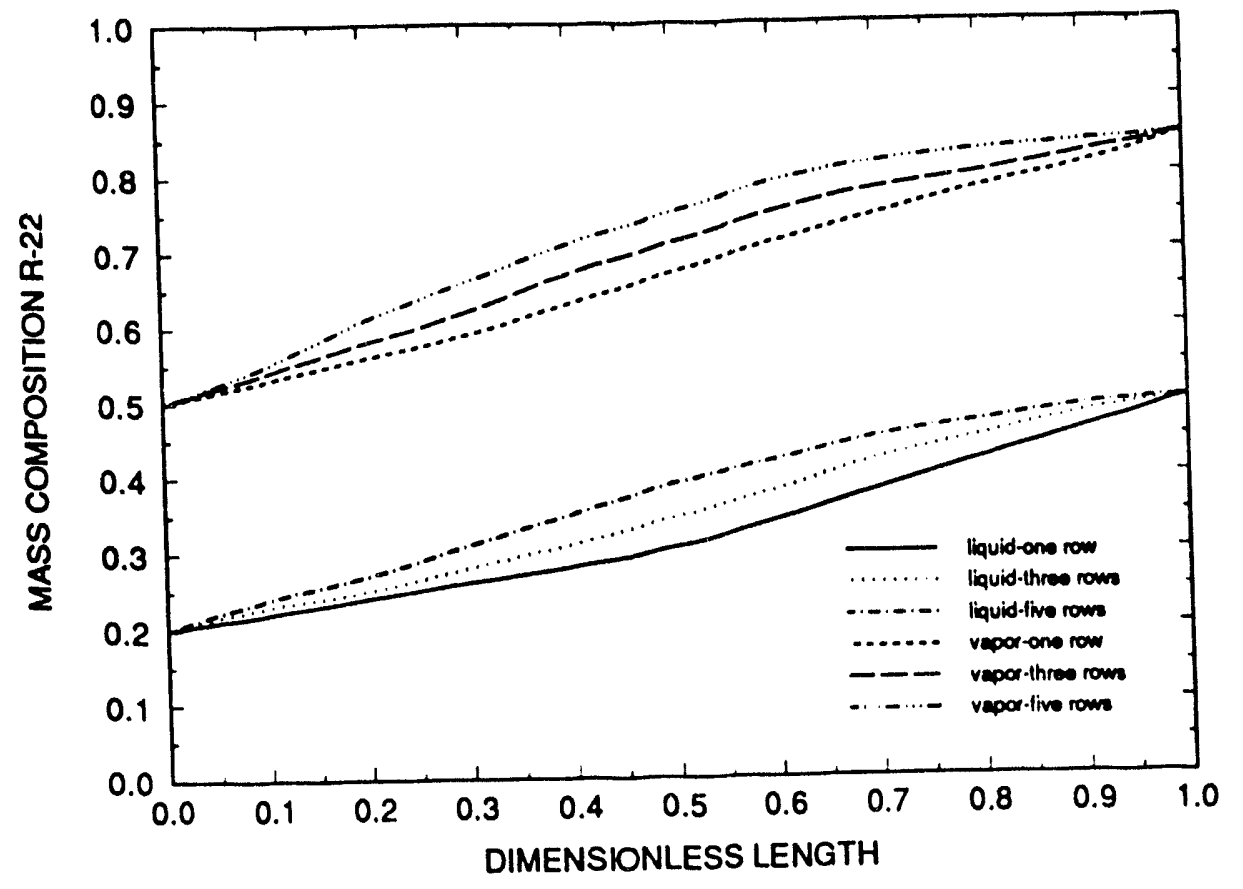

Figure 11 Refrigerant composition for plain-fin evaporator.

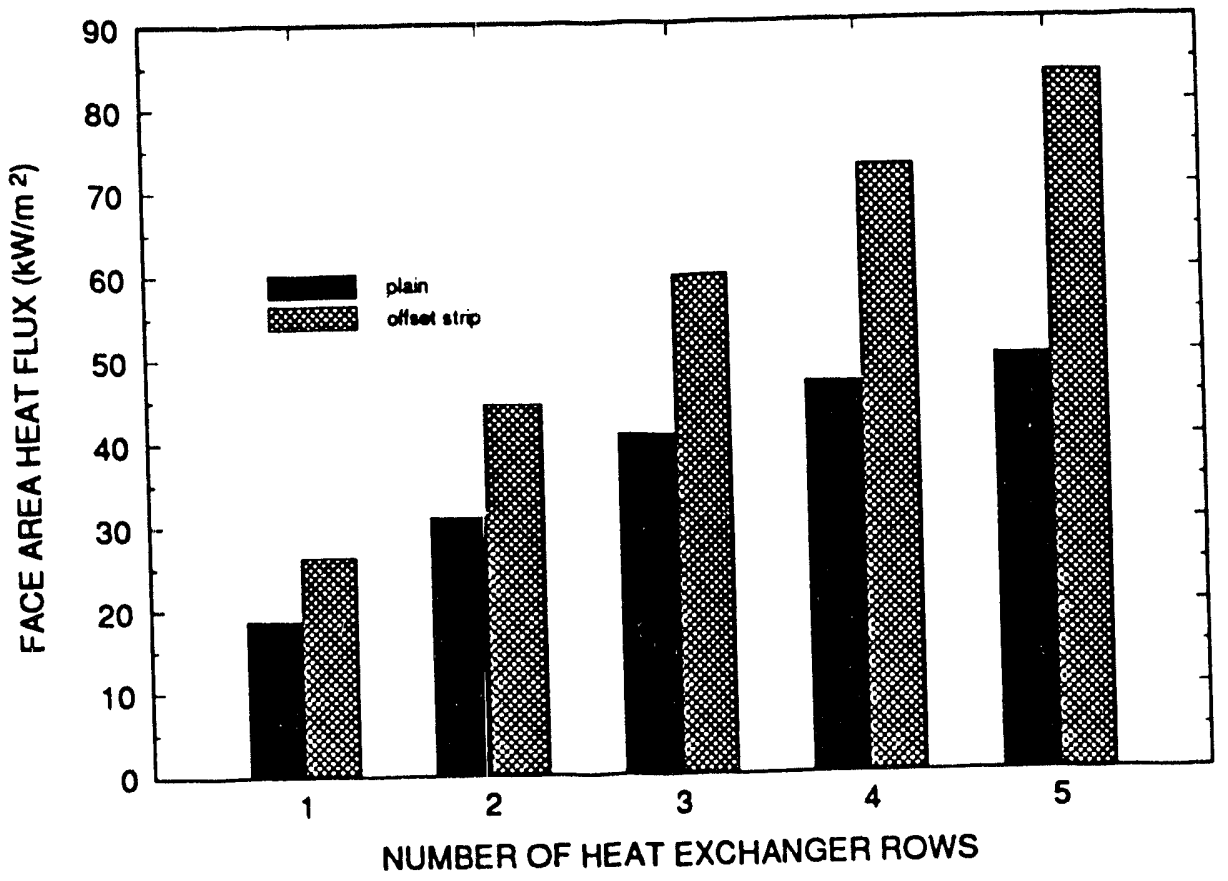

Figure 12 Heat exchanger face area heat flux. 


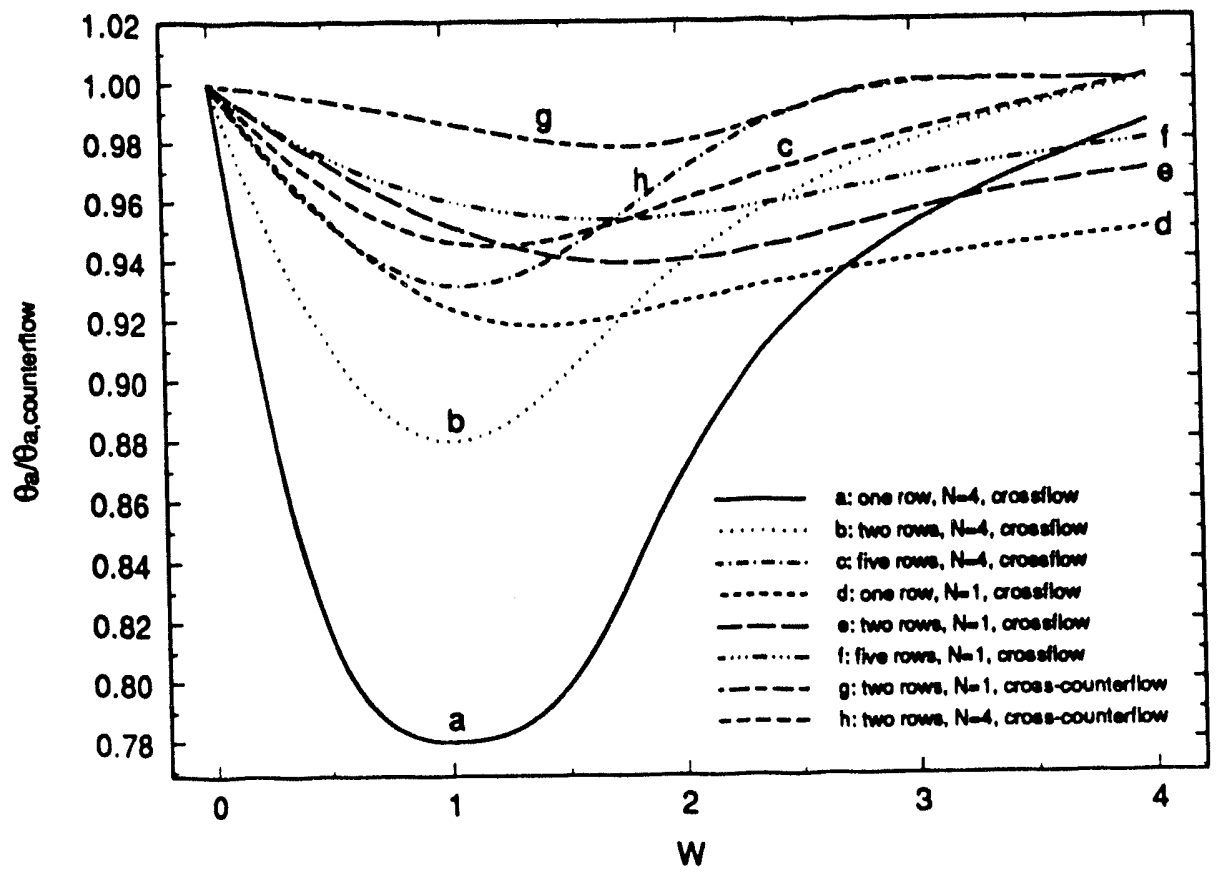

Figure 13 Relative effectiveness of heat exchanger arrangement.

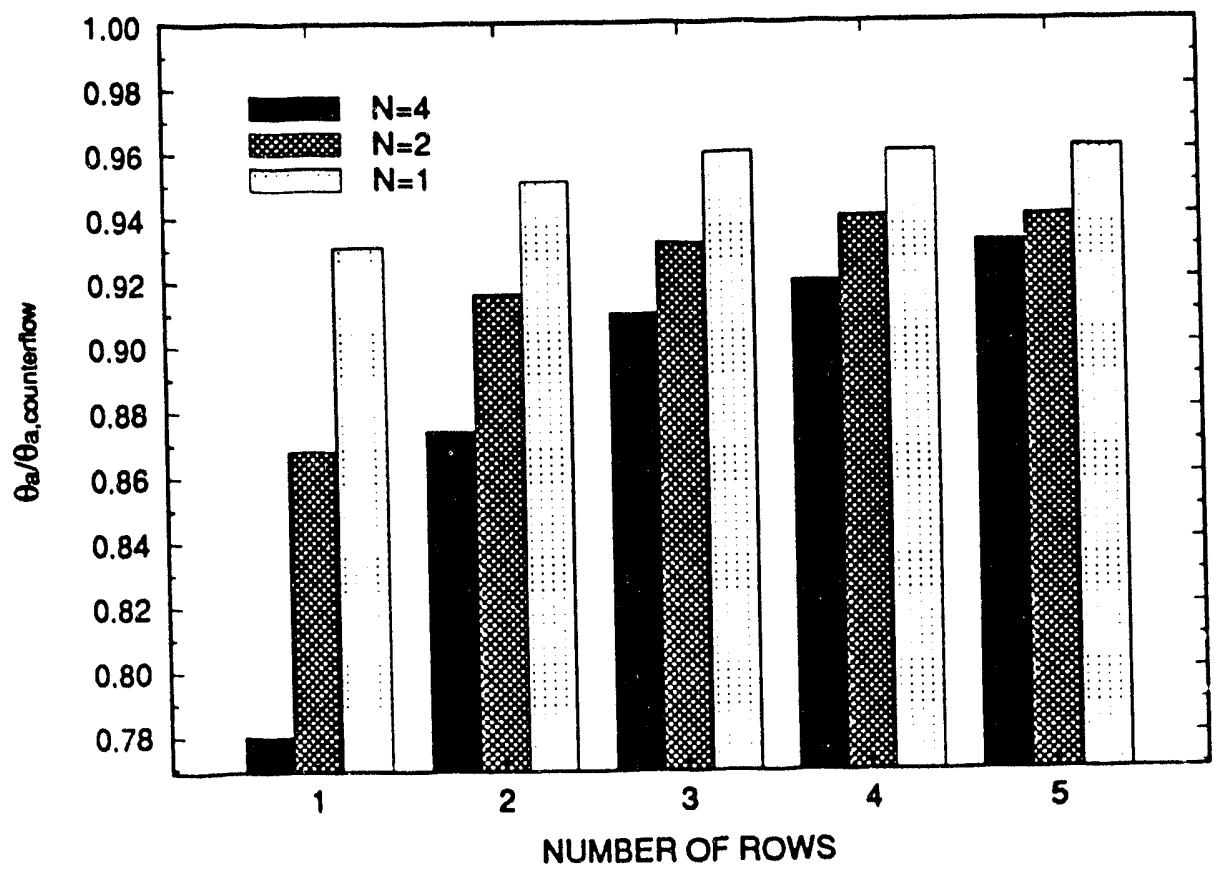

Figure 14 Relative effectiveness of crossflow, balanced evaporator. 


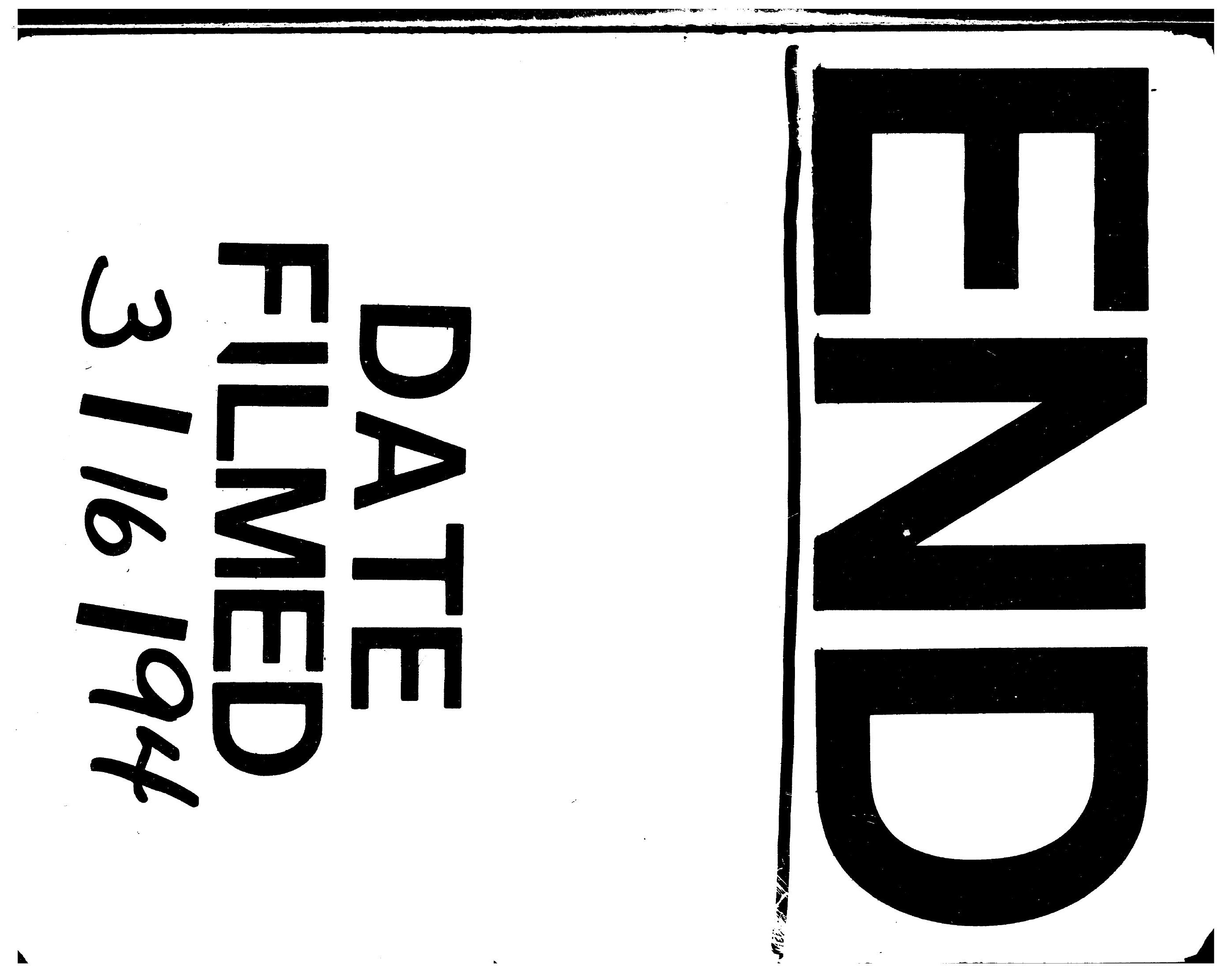



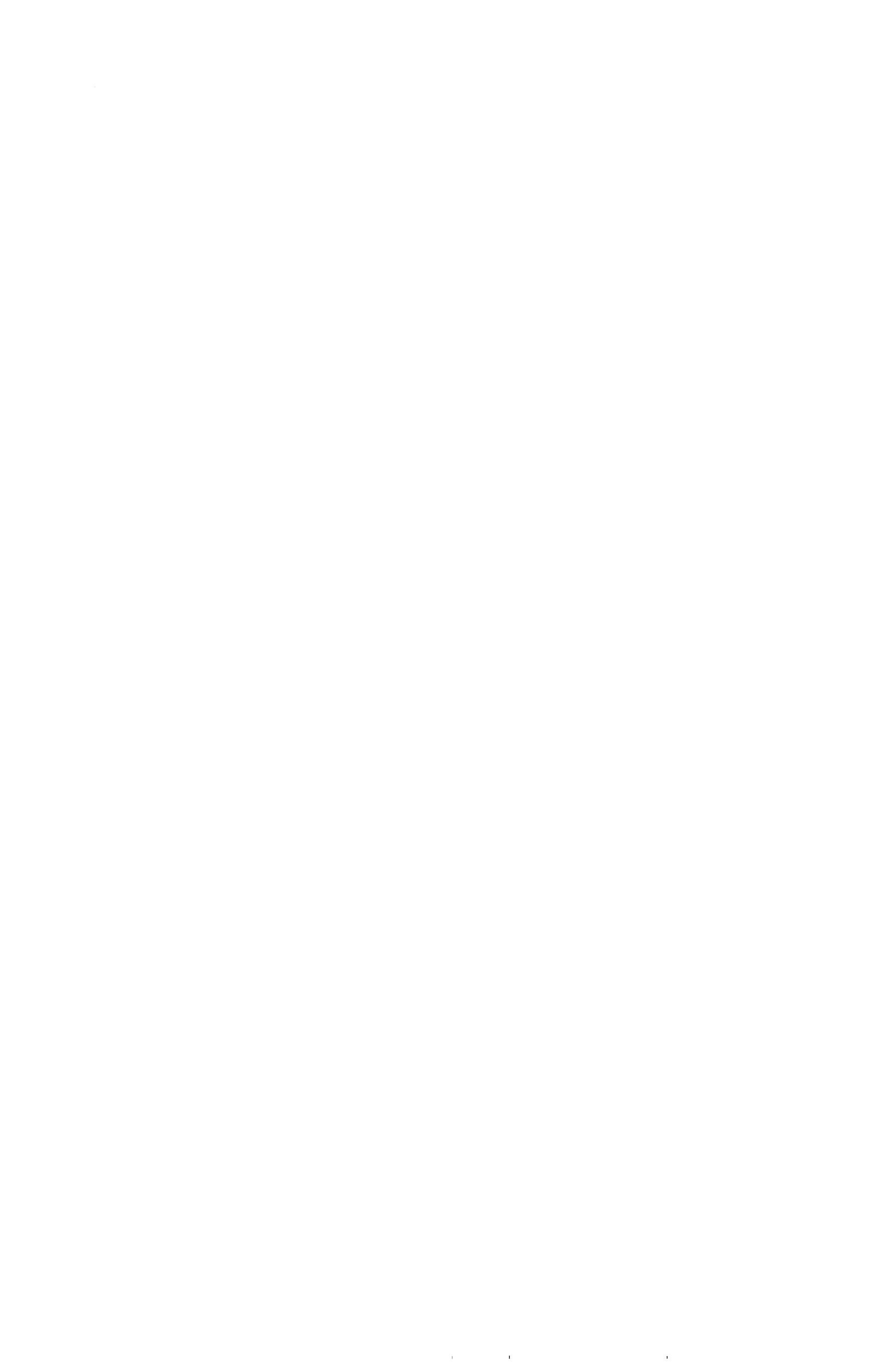